Available online at GSC Online Press Directory

GSC Biological and Pharmaceutical Sciences

e-ISSN: 2581-3250, CODEN (USA): GBPSC2

Journal homepage: https://www.gsconlinepress.com/journals/gscbps

(CASE REPORT)

\title{
A 16-year old man with an intradural extramedullary arachnoid cyst in the spine: a rare case
}

\author{
Yulia Damayanti $1{ }^{*}$ and Yuyun Yueniwati ${ }^{2}$ \\ ${ }^{1}$ Neurology Department, Faculty Medicine, Universitas Brawijaya, Malang, Indonesia \\ ${ }^{2}$ Radiology Department, Faculty Medicine, Universitas Brawijaya, Malang, Indonesia
}

Publication history: Received on 06 September 2020; revised on 27 September 2020; accepted on 28 September 2020

Article DOI: https://doi.org/10.30574/gscbps.2020.12.3.0290

\begin{abstract}
Intradural extramedullary arachnoid cyst in the spine is an extremely uncommon cyst, only 5\% occurs in the spine. This cyst rarely causes compression to the spinal cord. The etiology of this cyst is not known for certain, but the majority of which is congenital with other possible causes such as trauma, infection, inflammation, postoperative complication, and lumbar puncture. Arachnoid cyst is categorized into three types according to Nabor et al, which is type I (IA and IB), type II, and Type III. Diagnosis establishment was carried out through imaging modality of MRI with contrast. If the case is asymptomatic, observation as a conservative therapy is advised. Total cyst excision is recommended for patients with clinical symptoms and severe neurological damage. In this article, we report a case of a 16-year-old male patient who came with the main complaint of neck pain that radiated to the upper back, down to his arms and both of his hands for the past 4 months before hospital administration. This was followed by weaknesses in all of his extremities and difficulties when urinating and defecating. Based on MRI, C3-C5 intradural extramedullary arachnoid cyst was detected and the patient had undergone total cyst excision surgery with a promising result that shows the increased value for the four limbs and decreased pain. An intradural extramedullary arachnoid cyst is an extremely rare cyst. This case utilized MRI with contrast as the imaging modality, proving to be very helpful in establishing diagnosis.
\end{abstract}

Keywords: Arachnoid cyst; Rare cyst; Cyst excision; Intradural; MRI; Outcome

\section{Introduction}

Intradural extramedullary cyst in the spine is an extremely uncommon case and rarely causes spinal cord compression $[1,2]$. This cyst is suspected result from a congenital disorder of the dura mater and is almost always related to the intrathecal subarachnoid space via small defects in the dura mater. Several benign cystic lesions can appear in this location, e.g. arachnoid cyst, ependymal cyst, heterogeneous or neurenteric cyst, teratogenic cyst, and epithelial cyst [3]. These cysts have the same origin, except on small cases of arachnoid cysts appearing after trauma or arachnoiditis [2]. The following is a spinal cyst classification according to Nabor (table 1).

\footnotetext{
* Corresponding author: Yulia Damayanti

Program Study Spesialis Neurologi, Medical Faculty Universitas Brawijaya, Malang.

Copyright $(2020$ Author(s) retain the copyright of this article. This article is published under the terms of the Creative Commons Attribution License 4.0.
} 
Table 1 Classification of spinal cysts (adapted from Nabors et al).

\begin{tabular}{ll}
\hline Type & Description \\
\hline I & $\begin{array}{l}\text { Extradural meningeal cysts without spinal nerve root } \\
\text { fibers }\end{array}$ \\
\hline IA & Extradural meningeal/arachnoid cysts \\
\hline IB & Sacral meningocele \\
\hline II & $\begin{array}{l}\text { Extradural meningeal cysts with spinal nerve root fibers } \\
\text { (Tarlov perineural cysts) }\end{array}$ \\
\hline III & Spinal intradural arachnoid cysts \\
\hline
\end{tabular}

An intradural arachnoid cyst is made from arachnoid tissue, neuroepithelial intradural cyst, or ependymal cyst from ependymal tissue, intradural endodermal cyst, or heterogeneous cyst from the endodermal region [4]. This cyst will present clinical symptoms resulting from the compression on the spinal cord, therefore causing the neurologic deficit. The most common ones are slowly progressive myelopathy or myeloradiculopathy [2]. An intradural extramedullary arachnoid cyst is exceptionally rare to cause myelopathy or spinal cord compression, only $1-3 \%$ of the cases lead to spinal cord compression [3,5,7]. In many cases, compression on the spinal cord and shifting occurs due to this lesion, most of which are often found in the thoracic region [5].

Several sources mentioned that the appearance of these clinical symptoms due to spinal cord compression is caused by cyst expansion. The widely accepted mechanism is the enlargement by a one-way valve effect in cysts that communicate with the cerebrospinal fluid space through a fistula orifice, while another mechanism is based on a hyperosmotic or secretory theory in non-communicating arachnoid cysts that involve fluid productions by cyst wall cells [3]. The pathological process of cyst expansion can cause spinal canal expansion with pedicle erosion and thinning, interpedicular distance increase, and posterior vertebral wall scalloping with successive deformation and instability. Neurologically, cyst expansion can result in the compression of the spinal cord and/or spinal nerve root which leads to clinical symptoms, for instance, progressive pain, hypoesthesia, incontinence, paraparesis, or tetraparesis [3].

This cyst most often occurs on the middle and lower part of the spine (65\%), but there have been some reports of occurrence in the lumbar and lumbosacral region (13\%), thoracolumbar region (12\%), and sacral region (7\%), whereas it very rarely takes place in the cervical region. Other literature mentions that $80 \%$ of intradural arachnoid cysts are found in the thoracic vertebrae, $15 \%$ are found in the cervical region, and $5 \%$ are found in the lumbar region. The location of cysts in the vertebrae and spinal cord compression affects its clinical presentation. The symptoms can occur intermittently and can be worsened by gravitational position. Symptom remissions and fluctuations have been reported on approximately $30 \%$ of the cases $[1,2]$.

The etiology of this cyst has not been definitively determined. Although, the most probable explanations are congenital causes and the herniation of the arachnoid membrane (primary cyst). Several cases may be the result of trauma, postoperative complication, lumbar puncture, infections, or inflammations (secondary cyst) [1]. Because it is most frequently associated with congenital factors, arachnoid cyst often occurs at a young age, though some reports have been found on older ages and children [5]. Research conducted by Fam et al stated that the onset of arachnoid cyst is at the age of 53.4, ranging from the age of 34 to 91 [6].

Magnetic Resonance Imaging (MRI) is proven to be quite effective as the initial modality in diagnosing arachnoid cyst and it doesn't require the injection of intrathecal contrast media. MRI can also determine the anatomical relationship of the cyst with its surrounding structure [1,2]. Surgery has always been the best option of therapy when the patient exhibits neurologic deficit symptoms that grow increasingly worse due to spinal cord compression, showed by vertebral instability or cyst enlargement [2,3]. On asymptomatic patients, observation is recommended as conservative therapy [1]. This is a rare case report because Cyst is located in intradural and vertebra cervicalis so we must report this information. 


\section{Case report}

A 16-year-old male patient came to the emergency department with a complaint of not being able to move both of his hands and feet. The patient complained of gradual weaknesses in both hands and feet for the past 3 months, which worsened 2 weeks before hospital administration where he can no longer move both of his hands and feet. The patient also complained about radiating neck pain which initially extended to his left and right arm, down to both of his hands 4 months ago. Some degrees of pain was also felt in his upper back, which was mainly experienced after doing activities.

The pains were accompanied with numbness in both hands and the chest area. The patient also had difficulties when urinating and defecating one day before being administered to the hospital. There were no bumps on his back, no fever, no history of weight loss, no history of trauma, and no history of similar illness in his family. The patient is a first-year senior high school student.

Physical examination presented Glasgow Coma Scale (GCS) Eye (E) 4 Motorik (M) 5 Verbal (V) 6 with blood pressure at $110 / 70 \mathrm{mmHg}$, heart rate at 72 times per minute, and respiratory rate at 20 times per minute. Strength on both hands C5, C6, C7, C8, T1, and legs L2, L3, L4, L5, S1. Exteroceptive sensor: pain, temperature, touch decreased from the papilla mammae (T4) down. Position and vibration proprioception are interrupted. Autonomic dysfunction showed indications of retention URI et alvi. There was an increase of physiological reflects on the arm and limbs with positive Babinski reflex.

The radiological examination conducted was Anterior Posterior-lateral cervical X-ray with a result showing paracervical muscle spasm and suspected spondylodiscitis in the C5-C6 vertebral level. Head Computed Tomography (CT) scan without contrast didn't show an intraparenchymal brain lesion, which is then continued with a cervical MRI with contrast.

The result of cervical MRI with contrast displayed T1W1 hypointense lesion, T2W1/FS hyperintense lesion, nonrestricted DWI, non-blooming SWI, enhanced on its walls after providing contrasts on the intradural extramedullary region on the C3-C4 level, with a size $\pm 7.8 \times 5.3 \times 13,2 \mathrm{~mm}$ that pushes the spinal cord to posterior region, causing intense compression on that level and spinal cord edema in the C3-C5 level (T1W1 isointense, T2W1/T2FS hyperintense).

Conclusion: Intradural extramedullary cystic lesion in the C3-C4 level which causes severe spinal canal stenosis in that level and spinal cord edema in the C3-C5 level suspected of arachnoid cyst dd cystic ependymoma dd herniated ventral cord dd epidermoid cyst (figure 1,2).

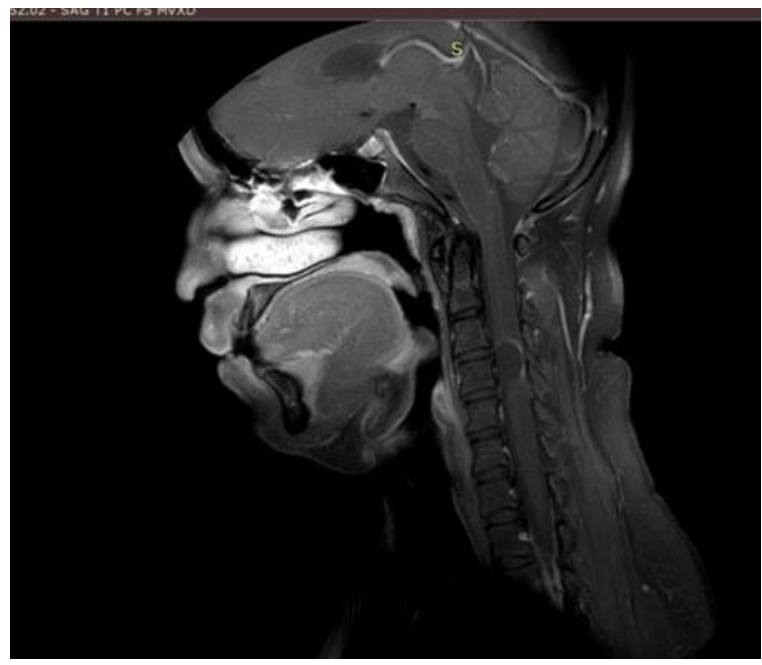

(A)

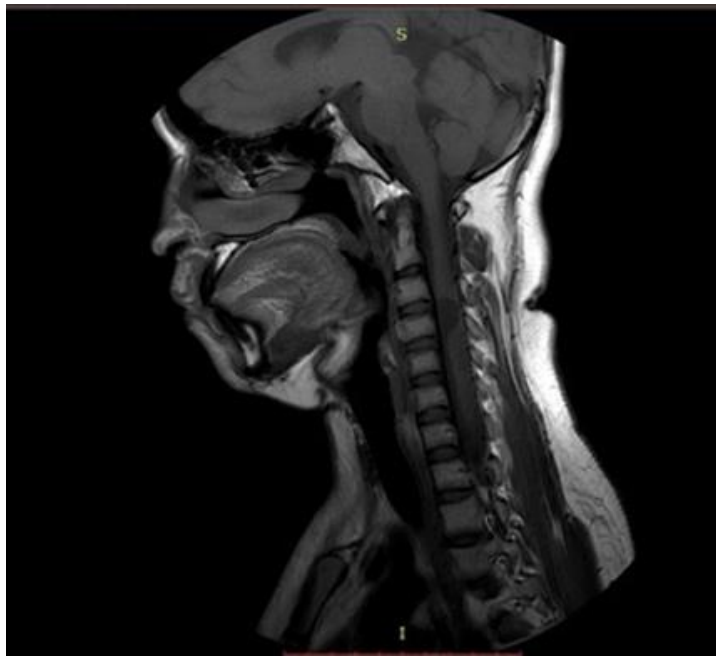

(B)

Figure 1 (A) Result MRI Cervical T1-weighted, (B) Result from MRI Cervical T1-weighted with contras 


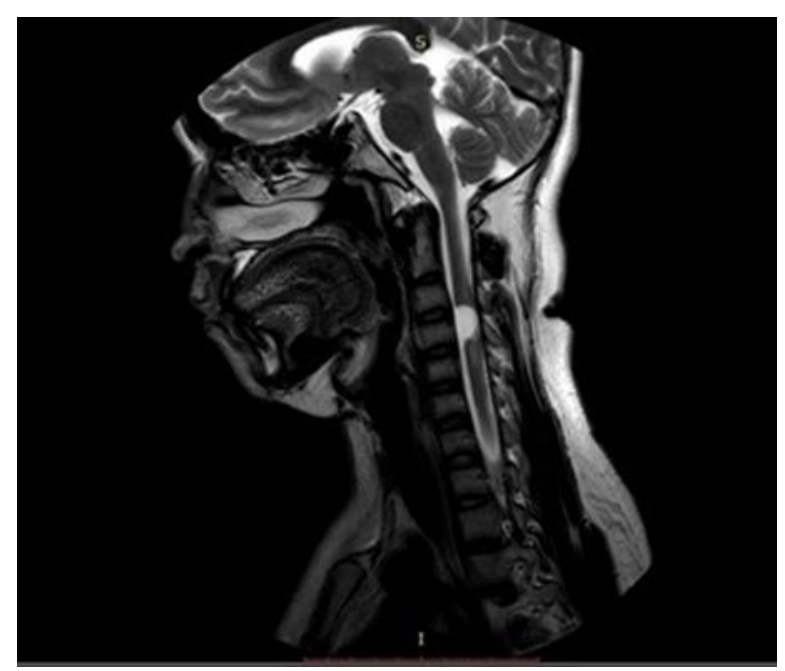

Figure 2 Result MRI Cervical T2-weighted

The patient was diagnosed with Upper Motor Neuron (UMN)-type Tetraplegia dt Susp Spinal Cord Tumor Intra Dural Extramedullar (IDEM) as a suspect for Arachnoid Cyst and he was planned to undergo elective tumor excision, posterior stabilization, corpectomy, and bone fusion.

The patient was given consultation at the neurosurgery division with suspicion of the arachnoid cyst and was advised for tumor excision. The patient underwent an operation and a $1 \mathrm{x} 2 \mathrm{~cm}$ cyst was found in the C3-C5 vertebrae with a welldefined border and histopathological examination showed results as follows (figure 3).

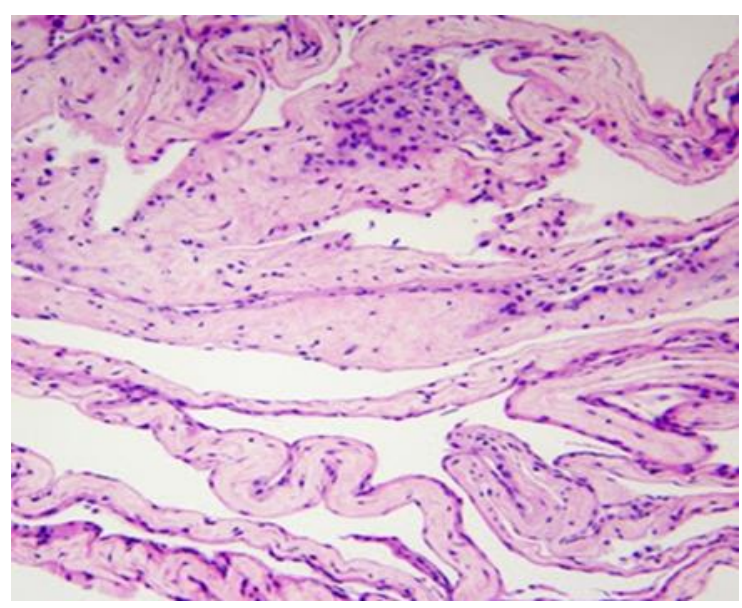

Figure 3 Histopathology arachnoid cyst

The cyst wall appeared to consist of a soft fibrous connective tissue membrane where the meningothelial cell layers are closely positioned. No signs of malignancy. Conclusion: Arachnoid Cyst. After the operation, the patient was treated where his pain decreased. General condition showing moderately ill. GCS E4V5M6 with blood pressure at $120 / 70$ $\mathrm{mmHg}$, heart rate at $72 \mathrm{x} /$ minute, and respiratory rate at 20 times per minute. The patient was sent home with strength on both hands C5, C6, C7, C8, T1 (1,1,1,1,1 right and left) and legs L2, L3, L4, L5, S1 (2,2,2,2,2 right and left).

\section{Discussion}

\subsection{Location}

$80 \%$ of the arachnoid cyst can be found in the thorax, $15 \%$ in the cervix, $5 \%$ in the spine [8]. The part of the spine in which the cyst is frequently found is in the middle and lower region of the spine (65\%), though there have been some 
reports of it occurring in the lumbar and lumbosacral region (13\%), thoracolumbar region (12\%), sacral region (7\%), and it rarely occurs in the cervical region [2,6]. This patient is an extremely rare case where the Arachnoid cyst is located in the intradural extramedullary region and the cervical vertebral region of the spine.

\subsection{Terminology and Classification}

Arachnoid cyst is first detected by Schlesinger in 1893 and first reported by Spiller et al in 1903. Based on different pathogenic conception, several terms such as "Arachnoid Diverticulum", Leptomeningeal Cyst", "localized adhesive arachnoiditis", and "spinal serious meningitis" have been used as another name for Spinal Arachnoid Cyst. Nabor et al classified spinal cyst into three types, namely type 1: extradural meningeal cyst without spinal nerve fiber (anterior and lateral meningococcus); type 2: extradural meningeal cyst containing spinal nerve fiber; type 3: intradural arachnoid cyst $[3,9]$. Based on the classification by Nabor, this patient's case falls into the spinal cyst type 3.

\subsection{Pathogenesis}

The pathogenesis of how spinal arachnoid cyst occurs is not entirely understood and is deeply multifactorial. Several theories mentioned that this arachnoid cyst is a congenital defect of the dura mater, and is always related to the subarachnoid space via small defects in the dura and herniation of the arachnoid [1,9]. Several cases may be the result of trauma, infections, inflammations, post-surgery complication, and lumbar puncture [1]. There was were no other predisposing factors. Therefore, the arachnoid cyst in this patient is deemed to be congenital or idiopathic.

\subsection{Clinical Features}

Funao et al stated that the average age of patients with the spinal arachnoid cyst is at the onset of 39,7 years old (with an age range of $22-60$ years old) [9]. Fam et al argued the onset of arachnoid cyst is at the age of 53,4 with an age range from 34 - 91 years old [6]. This patient was one of the rare cases in which the disease occurs at the age of 16.

Intradural arachnoid cyst in the spine is a very uncommon cyst and rarely becomes the cause of spinal cord compression which gives off myelopathy symptoms [1,2].

Based on reports, only 1 out of 290 intraspinal cysts produces symptoms [2]. Arachnoid cyst is one of the cyst types which causes spinal cord compression. Arachnoid cysts take place more frequently in extradural than intradural locations [8]. Clinical symptoms that emerge in patients with intradural extramedullary arachnoid cyst are pain (64\%), including back pain (46\%), extremity radiculopathy pain (9\%), and neck pain (9\%). Limb weaknesses can happen, and autonomic function dysfunction may arise, among which is urinary tract disorder. Final reported $50 \%$ of patients will suffer from the urinary tract and intestinal disorder [9].

Other emerging clinical symptoms that may appear are hypoesthesia, incontinence, paraparesis, or tetraparesis [3]. Wang et al have reported that intradural cyst located in the anterior region will present features consisting of extremities weakness and myelopathy, while cyst located in the posterior region will provide symptoms such as hypoesthesia and neuropathic pain [9].

Clinical symptoms found in this patient consisted of immense pain, especially after activities, that radiated from the neck down to the upper back, further spreading to both arms and hands. Weaknesses were found on both hands and feet which happened after the pain took place and grew more intense. Autonomic dysfunction found on the patient, consisting of retention uri and retention alvi, was identified after sensory and motor complaints.

\subsection{Imaging}

Extradural arachnoid cysts are much more common than intradural cysts. Based on research conducted by Nabor et al, 18 out of 22 patients were diagnosed with an extradural arachnoid cyst while only 4 of them have an intradural arachnoid cyst. Despite this, cases in children differ by a considerable margin where $58 \%$ of child patients have an intradural arachnoid cyst. This is likely due to the high occurrence of congenital malformations of the central nervous system in children $[1,2,9]$. The thoracic region has been reported to be the area in which intradural arachnoid cyst occurs most frequently with $78 \%$ involvement of the dorsal region. The reason why the intradural arachnoid cyst takes place more often in the dorsal region is that the dorsal column is the longest segment which also has a narrow spinal canal [9].

Thoracic cysts commonly occur on young teenagers, while thoracolumbar and lumbar cysts usually appear on adults in their 40s $[1,10]$. Magnetic Resonance Imaging (MRI) is useful in detecting the mass and consistency of the cerebrospinal fluid. MR, will identify hypointense on T1W1 and hyperintense on the T2W1 [11]. Myelography is suitable to detect the dural defect which makes it possible to provide an accurate diagnosis for this lesion [1,9]. In this case, the cyst is located 
in the cervical region, an area in which intradural arachnoid cyst rarely takes place. Cervical MRI had been conducted on this patient to help establish the diagnosis in addition to myelography.

\subsection{Management}

The selected therapy for patients with symptomatic neurological damage due to intradural arachnoid cyst in the spine is total cyst excision $[1,2,6,9,11]$. Aspiration and partial excision of the cyst wall are not advised and there have been reports of recurrence happening after total cyst excision $[9,11,13]$. Asymptomatic patients are only recommended observation as their conservative therapy [2]. Clinical symptoms found in this patient is the increasingly aggravating neurologic deficit-an indication of the need for surgery. This patient had undergone total excision on the entire arachnoid cyst wall.

\subsection{Outcome}

Several studies have reported favorable results after undergoing total excision of arachnoid cyst: complete disappearance of pain and no patients were experiencing a recurrence of cyst and kyphosis formation [7,9,11]. Funao et al deduced that patients with prolonged symptoms and a large cyst will produce less promising postoperative results. In his study, 12 patients with clinical symptoms of more than one year and cyst size larger than 5 vertebrae showed unfavorable results after their total cyst excision [9,12].

This patient's clinical symptoms and neurologic deficit occur for 4 months (less than one year) and the cyst involved only 3 vertebral segments. After having to go through total cyst excision, the patient has shown good results compared to before surgery: decreased pain and improved extremity strengths.

\section{Conclusion}

An intradural extramedullary arachnoid cyst is an extremely rare cyst. It is a type of cyst that is very uncommon to cause spinal cord compression and oftentimes, it is asymptomatic. The diagnosis of arachnoid cyst is based on the appeared clinical symptoms, physical examination, and histopathology. The therapy of choice when clinical symptoms appear, and spinal cord compression takes place which leads to the neurologic deficit is the total cyst excision. However, when the case is asymptomatic, then the therapy of choice is observation. This case utilized MRI with contrast as the imaging modality, proving to be very helpful in establishing diagnosis so that proper therapy management can be given according to the patient's condition, producing the most optimal result.

\section{Compliance with ethical standards}

\section{Acknowledgments}

Thankful to the Neurology Department and Radiology Department, Faculty of Medicine, Universitas Brawijaya - Saiful Anwar Hospital Malang for the opportunity given to make a case report

\section{Disclosure of conflict of interest}

This case report doesn't have a conflict of interest.

\section{Statement of ethical approval}

This case report has been accepted by the patient and the patient has been signed an informed consent form for the anonymous publication of medical data.

\section{Statement of informed consent}

Informed consent was obtained from all individual participants included in the study.

\section{References}

[1] Sahputra RE, Qorina S. Kista Arachnoid Ekstradural. Jurnal Kesehatan Andalas. 2018; 2: 74-79.

[2] Moses BZ, Friedman NG, Penn LD, et al. Intradural Spinal Arachnoid Cyst Resection: Implication of Duraplasty in a Large Case Series. J Neurosurg Spine. 2018; 28: 548-554. 
[3] Schmutzer M, Tonn JC, Zausinger S. Spinal Intradural Extramedullary Arachnoid Cysts in Adults: Operative therapy and clinical outcome. Springer. 2019.

[4] Moreno OC, Marin VC, Senar CA, et al. Radiological Diagnosis of Spinal Arachnoid Cysts: A Pictorial Essay. Journal of Medical Imaging and Radiation Oncology. 2016; 60: 632-638.

[5] David KS, Ebenezer S, Avellino MA. Symptomatic Spinal Cord Compression from an Intradural Arachnoid Cyst with Associated Syrinx in a Child: Case Report. Pediatric Neurosurgery. 2012; 48: 236-239.

[6] Fam DM, Woodroffe WR, Helland L, et al. Spinal arachnoid cysts in adults: diagnosis and management. A singlecenter experience. JNeurosurgery Spine. 2018; 29: 711-719.

[7] Maenhoudt W, Rasschaert R, Bontinck H, et al. Post-Arachnoiditis Anterior Spinal Arachnoid Cyst Formation with Compressive Myelopathy: Report of 2 cases. World Neurosurgery. 2018; 18: 1-8.

[8] Tureyen K, Senol N, Sahin B, et al. Spinal Extradural Arachnoid Cyst. The Spine Journal. 2010; 9: e10-e15.

[9] Garg K, Borkar AS, Kale SS, et al. Spinal Arachnoid Cysts-Our Experience and Review of Literature. British Journal of Neurosurgery. 2016; 720: 1-7.

[10] Yueniwati Y, Apprianisa A. The Correlation between Petrous Part of the Temporal Bone Density and the Internal Auditory Canal Diameter in Sensorineural Hearing Loss Patients with Chronic Renal Failure, Indian Journal of Otolaryngology and Head \& Neck Surgery. 2019; 1-6.

[11] Kahramans, Aniki, Sirins et al. Extradural giant multiloculated arachnoid cyst causing spinal cord compression in a child. J Spinal Cord Med 2008; 31: 306-308.

[12] Yueniwati Y, Christina E. The challenges in differentiating tuberculous from pyogenic spondylitis using magnetic resonance imaging, Reports in Medical Imaging, 2017; 10: 34-43.

[13] Filho A, Silva H, Sciubba MD, et al. Giant Intradural Extramedullary Arachnoid Cyst of the Thoracic Spine. Journal of Clinical Neuroscience. 2009; 16: 1369-1371.

\section{Author's short biography}

\section{Yulia Damayanti}

Neurology Resident, Neurology Department, Faculty of Medicine, Universitas Brawijaya - Saiful Anwar Hospital Malang, Indonesia.

\section{Yuyun Yueniwati}

Professor in Neuroradiology - Head and Neck Radiology from Radiology Department, Faculty of Medicine, Universitas Brawijaya - Saiful Anwar Hospital Malang, Indonesia. Research interest: Radiology (Neuroradiology Head and Neck Radiology) ; Medical Technology and Genetics. 